\title{
LCA as an element in environmental management systems - comparison of conditions in selected organisations in Poland, Sweden and Germany
}

\author{
Part 1: Background and initial assumptions
}

\author{
Anna Lewandowska $\cdot$ Przemyslaw Kurczewski • \\ Joanna Kulczycka $\cdot$ Katarzyna Joachimiak • \\ Alina Matuszak-Flejszman • Henrikke Baumann • \\ Andreas Ciroth \\ Received: 2 September 2011 / Accepted: 17 July 2012 \\ (C) The Author(s) 2012. This article is published with open access at Springerlink.com
}

\begin{abstract}
Purpose In this two-part paper (Background and Initial Assumptions (part 1) and Results of Survey Research (part 2)), we present surveys whose main objective is to determine whether, and to what extent, the life cycle assessment (LCA) technique is used for the identification and assessment of environmental aspects in environmental management systems (EMS) and whether there are any differences in this respect between the companies and countries analysed.
\end{abstract}

Responsible editor: Gerald Rebitzer

A. Lewandowska $(\bowtie) \cdot$ K. Joachimiak $\cdot$ A. Matuszak-Flejszman Faculty of Commodity Science, Poznan University of Economics, al. Niepodleglosci 10,

Poznan 61-875, Poland

e-mail: anna.lewandowska@ue.poznan.pl

P. Kurczewski

Faculty of Machines and Transportation,

Poznan University of Technology,

ul. Piotrowo 3,

Poznan 60-965, Poland

J. Kulczycka

Mineral and Energy Economy Research Institute,

Polish Academy of Science,

ul. Wybickiego 7,

Krakow 31-261, Poland

H. Baumann

Energy and Environment Division,

Chalmers University of Technology,

41296 Gothenburg, Sweden

A. Ciroth

GreenDeltaTC GmbH,

Raumerstrasse 7 ,

10437 Berlin, Germany
Methods The survey research was carried out using the computer assisted self-administered interviewing method among selected Polish, German and Swedish organisations which implement EMS in accordance with the requirements of ISO 14001 and/or the EMAS regulation.

Results The organisations investigated, regardless of their country, are dominated by qualitative and semi-quantitative techniques of assessment and identification of environmental aspects. LCA was used sporadically, although some differences can be observed between the countries analysed.

Conclusions The environmental managers accustomed to traditional qualitative and semi-quantitative solutions have not been given preparation to enable them to understand and adopt different approaches such as LCA. On the other hand, representatives of the organisations investigated declared that they were ready to accept an even longer timescale for the identification and assessment processes relating to environmental aspects, which represents a potential opportunity for LCA. The more precise understanding and definition of environmental problems that are precisely defined in LCA would represent a novelty for environmental managers. In practice, environmental problems are defined in a general sense and rather ambiguously, as this level of detail is sufficient in the context of qualitative and semi-quantitative techniques commonly used for the identification and assessment of environmental aspects.

Keywords Assessment · Environmental aspects · Identification $\cdot$ Life cycle assessment

\section{LCA applications}

Life cycle assessment (LCA) addresses the environmental aspects and potential environmental impacts (e.g. use of 
resources and the environmental consequences of releases) throughout a product's life cycle from raw material acquisition through production, use, end-of-life treatment, recycling and final disposal (ISO 14040:2006). LCA belongs to those tools, such as eco-labelling and eco-design, that are designed to undertake an ecological assessment of products. In addition, a characteristic feature of the technique is the analysis of environmental issues from the angle of function and an assessment in the perspective of the entire life cycle. There are numerous fields of application for LCA that differ in their scale and scope. The general division between public policy and business applications has been made in our paper.

\subsection{Public policy applications}

LCA may improve the public policy process by providing comprehensive environmental information for decision makers. Public policy decisions vary and can range from the implementation of narrow mandates to the development of broad policy statements. Life cycle thinking can also support environmental policy makers in moving from fragmented end-of-pipe and end-of-life approaches towards more integrated ones (Allen et al. 1995). There are numerous public policy applications where LCA can be used directly or indirectly, for example (Allen et al. 1995; Baumann and Tillmann 2004; ISO 14040:2006):

- Eco-labelling systems (ISO 14020, ISO 14021 and ISO 14025)

- Inclusion of environmental aspects in product standards (ISO Guide 64)

- Quantification, monitoring and reporting of facilities and projects relating to emission and absorption, validation, verification and certification of greenhouse gases (ISO 14064)

- Creating social policy

- Integrated Product Policy

- Green Public Procurement

- Policy and regulations

The popularity of eco-labelling systems can illustrate the different experiences of Poland, Germany and Sweden in using LCA in public policy. Apart from the EU Eco-label Flower, national eco-labelling systems exist in all the countries investigated (Blue Angel-Germany, Nordic Swan-Sweden and Eko-znak-Poland). According to the information derived from the Blue Angel website (http:// www.blauer-engel.de), the first basic award criteria were adopted by the Environmental Label Jury in 1978, and nowadays, 11,700 products and services in circa 120 product categories carry the Blue Angel eco-label. In the case of Sweden, the Nordic Eco-label was established in 1989 by the Nordic Council of Ministers, and 6,500 products are currently Nordic eco-labelled and marketed by about 1,100
Swedish companies (http://www.nordic-ecolabel.org). In Poland, the national eco-label system was introduced in 1995 by the Act on Testing and Certification and about 80 products have been awarded the eco-label so far (http:// www.pcbc.gov.pl/english). A similar situation can be observed in relation to type III eco-labelling-Environmental Product Declarations. In contrast to their great popularity in Sweden, only two environmental type III declarations were developed for organisations operating in Poland.

\subsection{Business applications}

LCA can be used on a micro-scale in relation to a single product or a group of products where it constitutes an element of internal decision-making processes ( $\mathrm{R} \& \mathrm{D}$, eco-design) or a part of the company's external communications (green marketing, business social responsibility and product-oriented information systems). LCA can be combined with other tools like life cycle costing and social LCA to produce a life cycle sustainability assessment of products, called a LCSA (Klöpffer 2008; Swarr et al. 2011). There are also practical examples of using an extended version of LCA which, after linkage with toxicity potential, risk potential and cost data, can be applied as an eco-efficiency measure (BASF Eco-Efficiency Analysis method (Shonnard et al. 2003)). Appendix A of the ISO 14040 standard includes several examples of companyrelated LCA applications (ISO 14040:2006):

- Development and improvement of products

- Strategic planning

- Marketing

- Design for environment (ISO 14062)

- Environmental communications (ISO 14063)

- Environmental management systems and assessment of effects of environmental activities (ISO 14001, ISO 14004 and ISO 14031), e.g. identification of significant environmental aspects of the products and services of an organisation

From the point of view of this paper, the last of the above-mentioned aspects is the most significant one, as it gives a straightforward indication of the possibilities of using an LCA in environmental management systems for the identification and assessment of environmental aspects. Surveys performed by Baumann (1996), Frankl and Rubik (1999, 2000), Wilfried (2005) and Klöpffer and Grahl (2009) in Germany and Sweden proved the existence of LCA in industry and business in these countries. In Poland, by contrast, LCA is still more present in scientific and research activities (Bieda 2011; Czaplicka 2004; Kulczycka 2009; Kurczewski and Lewandowska 2010), despite the fact that the first work on this issue was written at the end of the 1990s of the twentieth century (Klos 1999, 2000). Poland, Germany and Sweden differ also with 
Fig. 1 The number of ISO 14001 certificates granted in Germany, Sweden and Poland in the years 1999-2009 (ISO 2010)

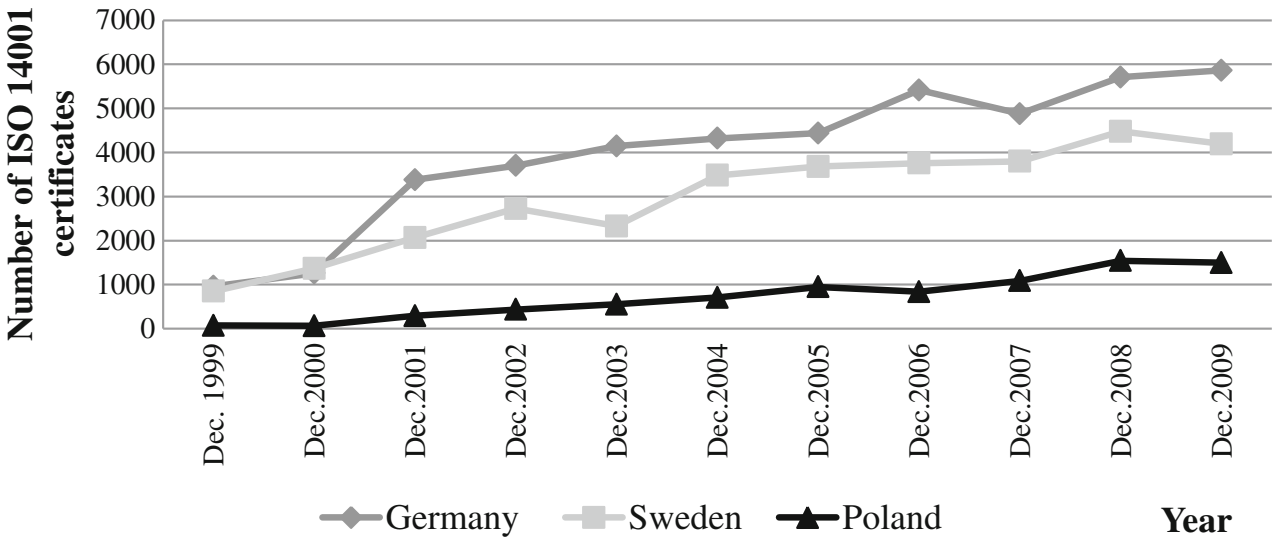

respect to their environmental management system experience. Germany and Sweden have for years belonged to the group of countries with the largest number of ISO 14001 certificates granted in Europe, whereas interest in such systems in Poland is still visibly lower. Figure 1 presents the number of ISO 14001 certificates granted in the countries analysed in the years 1999-2009 (data for December of each year). In 2009 , there were 5,865 certificates granted in Germany, 4,193 certificates granted in Sweden and 1,500 certificates granted in Poland (ISO survey 2009). As seen in Fig. 1, a similar disproportion was maintained over a period of 10 years. The analogical situation can be observed in relation to environmental management systems (EMS) complying with the EU Eco-Management and Audit Scheme (EMAS) regulation. In the period analysed, there were 1,408 organisations of this type with an eco-management and audit system (EMAS Register 2009) in Germany, 75 organisations in Sweden and 20 organisations in Poland.

Considering the above-mentioned differences, it has been assumed that it is worth examining and verifying whether the disproportions in experience in the above-mentioned countries, both in relation to EMS, eco-labelling and LCA, translate into the degree of use of the technique for the identification and assessment of environmental aspects. It may be assumed that LCA is commonly used in Germany and Sweden for other more evident purposes such as ecodesigning, ecological marketing, etc. The specificity of use of LCA in EMS involves using the tool within a system directed at an organisation, with the result that even those environmental managers, who are acquainted with LCA, may not always be aware of the possibility of using the tool within EMS. This topic is a valuable one for research because:

- The issue of the application of LCA for the identification and assessment of the environmental aspects in EMS is rarely tackled and discussed in the literature. There are only a few publications relating to the issue that prove (Lundberg 2007; Zobel et al. 2002, 2004; Frankl and Rubik 2000) that is it worth taking a greater interest in it because of its potential and of the powerful features of the LCA technique in this respect (Lewandowska et al. 2011).

- There is an increased interest in product-oriented environmental management systems (Rocha and Brezet 1999; de Bakker et al. 2002; Ammenberg and Sundin 2005; Donnelly et al. 2006) and product-oriented information systems (Wilfried 2005), where the role of LCA is evident.

- There is an absence of comprehensive information obtained from organisations which have implemented environmental management systems and relating to techniques used for the identification and assessment of aspects and the use of LCA in this respect.

- There is an absence of comprehensive research carried out on companies and relating to the type of environmental information that most often constitutes the basis for the assessment and selection of significant environmental aspects.

- There is an absence of information concerning possible differences in the degree of awareness and use of LCA in EMS between various countries.

This paper presents the results of research which is a continuation of work already undertaken (Lewandowska

Table 1 Population and research sample in the survey carried out (ISO 2010; EMAS register)

\begin{tabular}{llll}
\hline Country & $\begin{array}{l}\text { Number of } \\
\text { organisations } \\
\text { in the population }\end{array}$ & $\%$ & $\begin{array}{l}\text { Number of } \\
\text { organisations } \\
\text { in the sample }\end{array}$ \\
\hline $\begin{array}{l}\text { Germany } \\
\text { ISO 14001 }\end{array}$ & 5,865 & 44.90 & 587 \\
EMAS & 1,408 & 10.78 & 141 \\
Sweden & & & \\
ISO 14001 & 4,193 & 32.10 & 419 \\
EMAS & 75 & 0.57 & 8 \\
Poland & & & \\
ISO 14001 & 1,500 & 11.48 & 150 \\
EMAS & 20 & 0.15 & 2 \\
Total & 13,061 & 100.00 & 1,306 \\
\hline
\end{tabular}




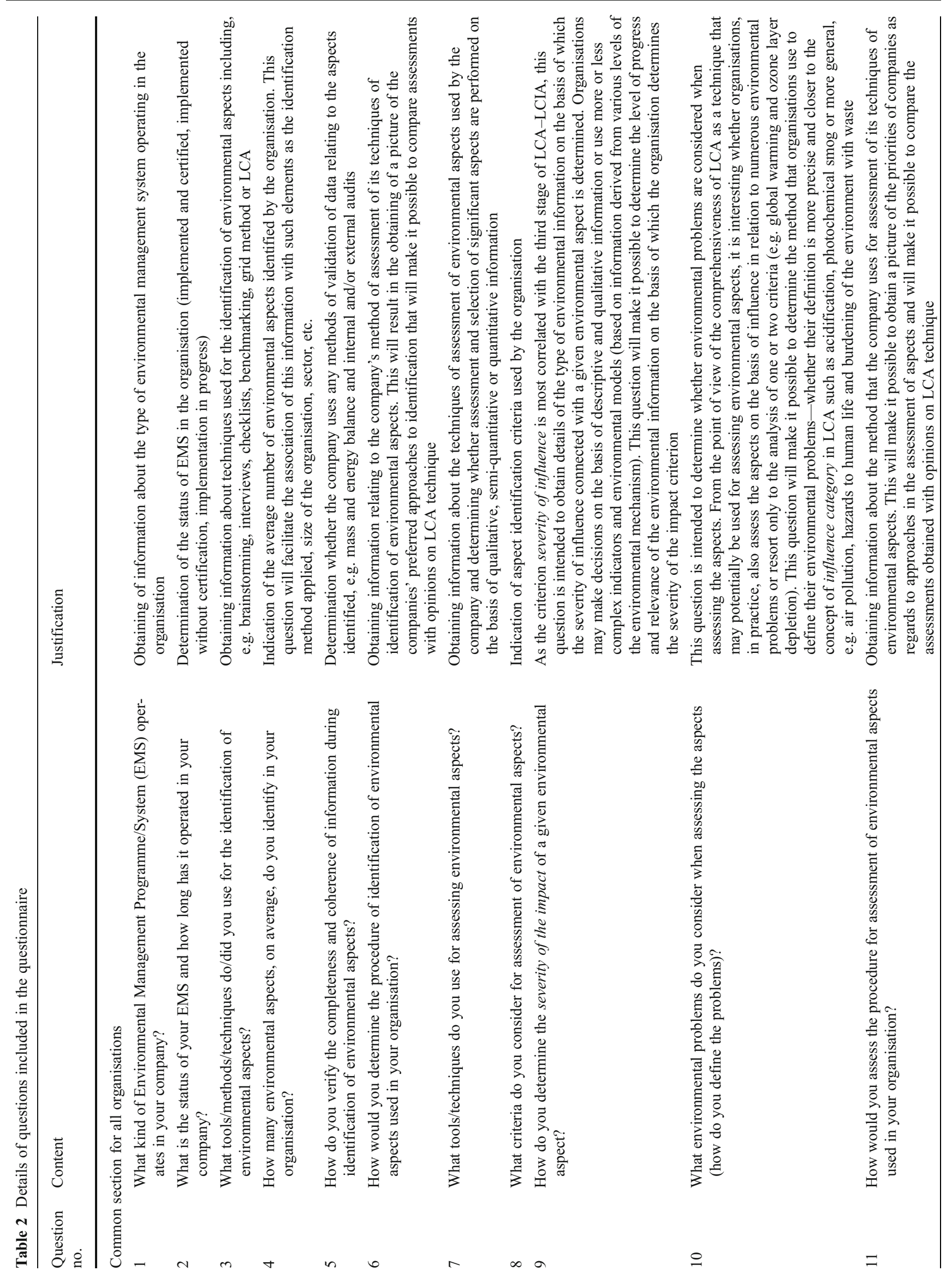




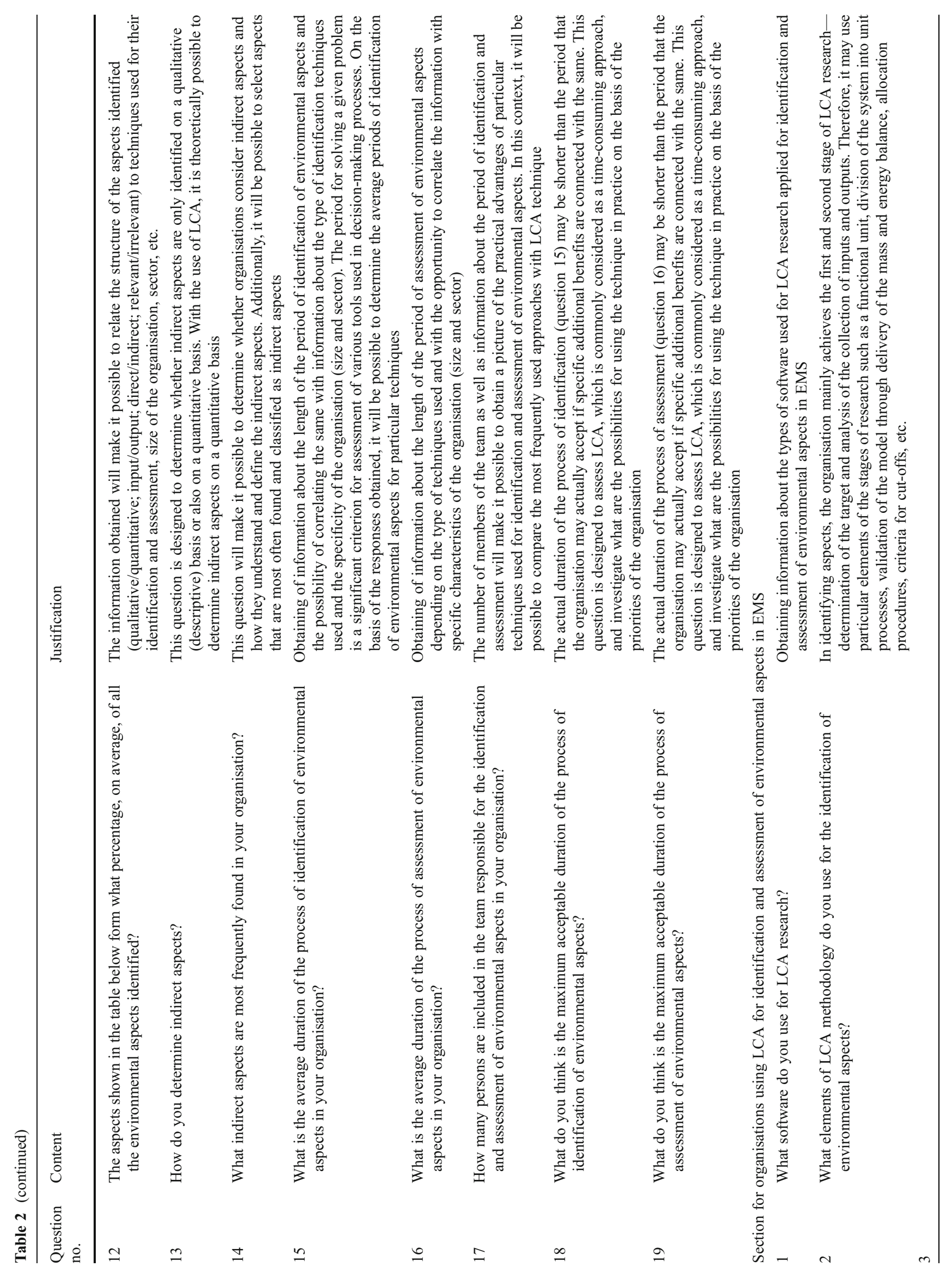




\begin{tabular}{|c|c|c|}
\hline 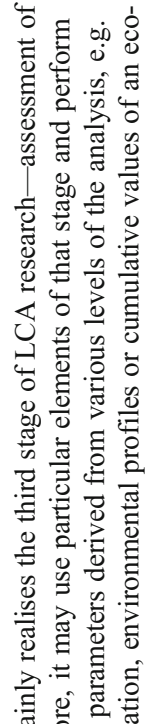 & 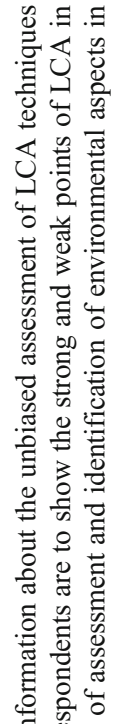 & $\begin{array}{l}\text { 2011; Lewandowska et al. 2011) where LCA was discussed } \\
\text { as a tool with the potential to be used for analysing the } \\
\text { environmental aspects in EMS. A general division into } \\
\text { input- and output-related environmental aspects was sug- } \\
\text { gested in our previous publications. In order to assess the } \\
\text { first category of aspects, "a cradle to gate LCA" could be } \\
\text { applied, while in relation to the second category of aspects, } \\
\text { "a gate to grave LCA" would be used. This way, the whole } \\
\text { of the system to be analysed could be covered by "a cradle } \\
\text { to grave" perspective. Insofar as the previous work related } \\
\text { to theoretical deliberations upon the utility and methodolog- } \\
\text { ical "readiness" of LCA to be used in EMS for the identifi- } \\
\text { cation and assessment of environmental aspects, this paper } \\
\text { presents the results of an actual assessment of the use of this } \\
\text { tool in practice by companies which had implemented en- } \\
\text { vironmental management systems. }\end{array}$ \\
\hline
\end{tabular}

\section{Survey}

In the survey which was conducted, the entire population consisted of all organisations operating in the three abovementioned countries that had implemented environmental management systems complying with the ISO 14001 requirements or the EMAS regulation (as of 2009) during the period of the survey. Systems complying with cleaner production and responsible care programmes were of lesser interest. The count of the entire population produced a total of 13,061 organisations (Table 1). Furthermore, percentage shares for particular countries and EMS types were determined, and by taking account of the percentage shares, the research sample was selected in such a manner as to constitute $10 \%$ of the population count. Consequently, survey questionnaires were sent to 1,306 organisations (587 German organisations with ISO 14001, 141 German organisations with EMAS, 419 Swedish organisations with ISO 14001, 8 Swedish organisations with EMAS, 150 Polish organisations with ISO 14001 and 2 Polish organisations with EMAS; see Table 1). Contact data were available for the entire population in the case of all organisations with EMAS as well as German and Swedish companies with ISO 14001. In the case of Polish organisations with ISO 14001, the database was available for 400 companies. A random sample was selected from the available data and the choice of every unit was equally probable.

The survey research was conducted using the computer assisted self-administered interviewing method. Survey questionnaires were sent to respondents by electronic mail on two occasions in the period from September to November 2010. The environmental managers responsible for EMS implementation were the target group in the survey. The surveys were prepared in such a manner as to enable their completion and return in electronic form without the need to print the response. In the event of an absence of response, randomly 


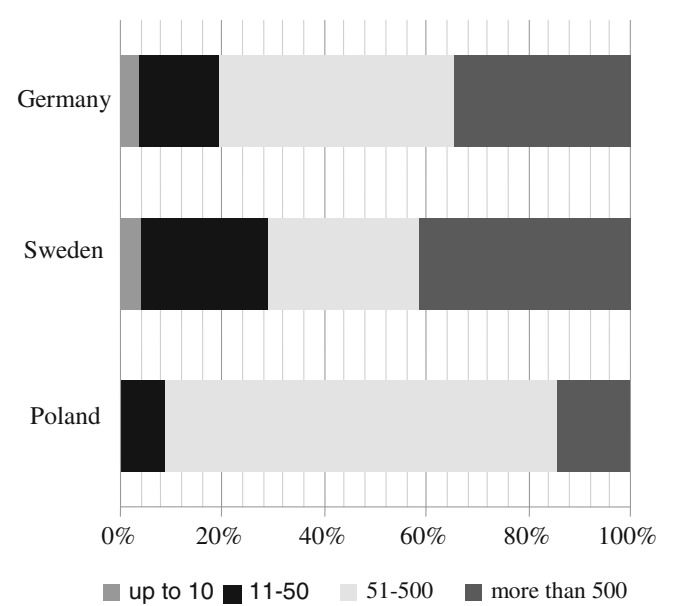

Fig. 2 Size of organisation (according to the number of employees)

selected companies were contacted by telephone and encouraged to participate in the survey. The basic research was preceded by a pilot research conducted in August 2010 in a selected group of organisations. They showed that the questionnaire is clear and comprehensible for respondents and it requires little editorial correction. The pilot research conducted with the use of the internet questionnaire method was supported by personal interviews with environmental managers from selected companies. They confirmed the transparency and clarity of the questions included in the questionnaire.

\subsection{Questionnaire}

A questionnaire consisting of two sections was used in the research. The first section was common for all companies and included 19 questions while the second part was only used for organisations applying LCA to the identification and assessment of environmental impacts and included four questions. The questionnaire included 4 closed (17\%) and 19 open questions $(83 \%)$. It also included shortened particulars which included questions concerning the size of the company (the

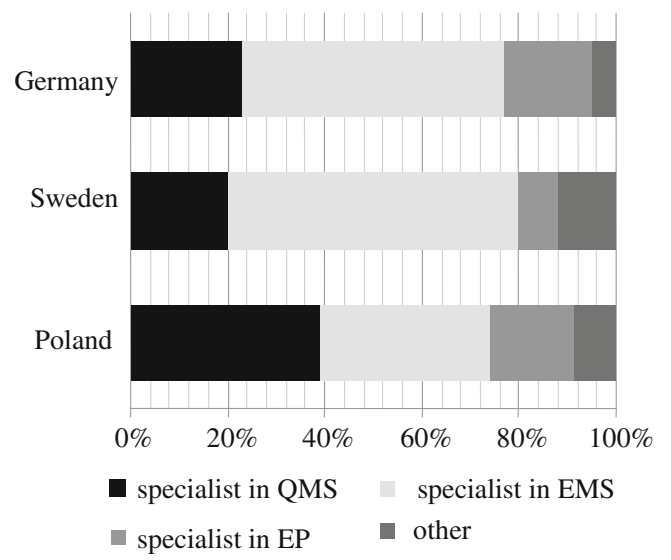

Fig. 3 Professional profile of persons filling out the questionnaires

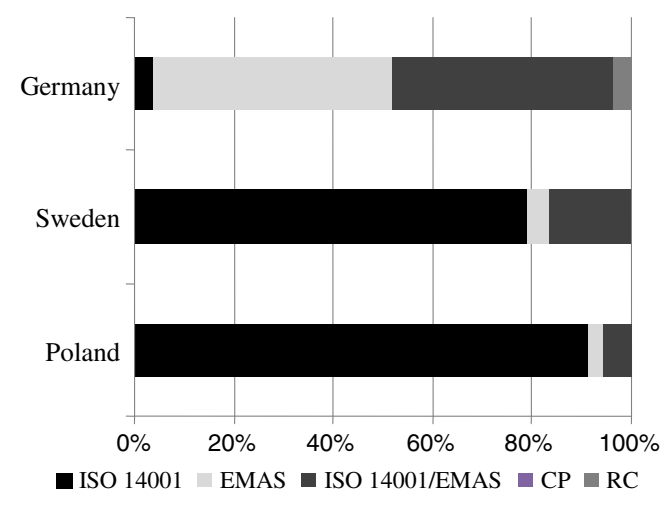

Fig. 4 Type of EMS in the organisations analysed

number of employees), professional profile of the person filling in the questionnaire and the sector in which the organisation was operating (according to NACE). Table 2 below includes details of the individual questions included in the questionnaire.

\subsection{Characteristics of organisations participating} in the research

As noted above, a total of 1,306 questionnaires were sent, out of which 727 questionnaires were sent to German organisations, 427 to Swedish organisations and 152 to Polish organisations in proportion to the number of EMS certificates in each of the countries. The percentage return obtained was $3.57 \%$ for Germany (26 organisations), $5.62 \%$ for Sweden (24 organisations) and $23.02 \%$ for Poland ( 35 organisations). There were 85 returned and correctly completed questionnaires in total. As shown in the data in Fig. 2, the questionnaires were mostly completed by medium and large companies (with over 50 employees). In accordance with the instructions included in the cover letter attached to the questionnaire, the questionnaires were mostly completed by specialists in EMS and quality management, rarely by specialists in environmental protection or persons with other professional profiles (technologists and

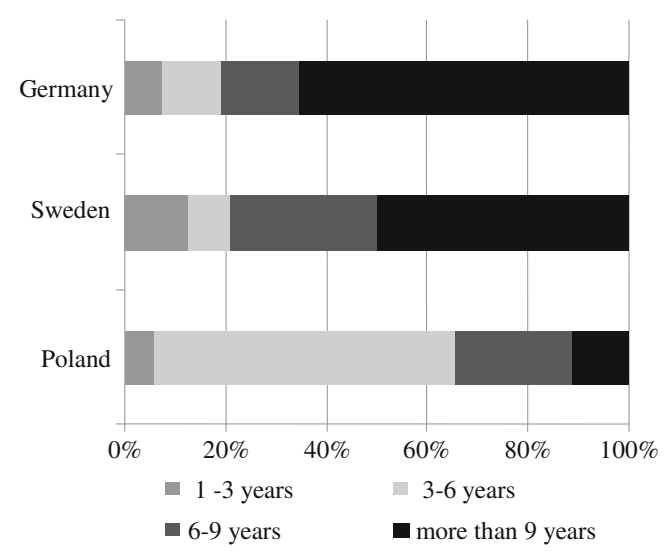

Fig. 5 Maturity of EMS in the organisations analysed 
executive representatives; Fig. 3). It is worth mentioning that the questionnaires were often filled out by two or three persons, which should not, however, be interpreted as a risk of double counting but rather as proof of the interdisciplinary and comprehensive character of the questionnaire.

According to the sample structure presented in Table 1, the questionnaires returned from Poland and Sweden were mostly returned by organisations that only have an environmental management system complying with the requirements of ISO 14001 (32 companies from Poland and 19 companies from Sweden). Other organisations from those countries returning questionnaires included those that have implemented eco-management and audit systems complying with the EMAS regulation (one organisation in Poland and one organisation in Sweden) as well as organisations that have implemented both types of EMS (two Polish companies and four Swedish companies). In the case of Germany, the questionnaires were sent back by 12 companies which have implemented both ISO 14001 and EMAS, 13 companies with EMAS only and by 1 company that only had a system complying with the requirements of ISO 14001 (Fig. 4). Environmental management systems were implemented and certified by an independent party in all the organisations analysed.

The results presented in Fig. 5 show the duration of operation of EMS in the organisations analysed. The results show that environmental management systems of the Polish companies analysed have operated for a shorter period of time, mainly for 3-6 years ( $60 \%$ of the respondents) and to a lesser degree from 6 to 9 years ( $20 \%$ of the respondents). In total, $15 \%$ of Polish companies responding have operated EMS for over 9 years. The Swedish and German organisations showed longer experience and more mature systems. Such systems have mainly operated for a period of 6-9 years or for more than 9 years (totalling about $80 \%$ of German and Swedish organisations analysed).

\section{Conclusions}

The fundamental observation resulting from the analysis performed is the low tendency of organisations to participate in the survey research. Despite the significant number of companies to which the questionnaire was sent and rather simple method of completing the questionnaire (the questionnaire was delivered electronically and without any need to print it out), there was a low level of feedback (especially in the case of Germany and Sweden). One of the many reasons for this situation could be the comprehensive content of the questionnaire that was often filled out by two persons and could be recognised as too time consuming. Corporate policies on internal confidentiality could be another reason for a lack of willingness to release sensitive data (two German companies only completed part of the questionnaire for this reason). Due to the low return rate, the results obtained may only refer to the organisations analysed and any generalisations should be made with caution.

Open Access This article is distributed under the terms of the Creative Commons Attribution License which permits any use, distribution, and reproduction in any medium, provided the original author (s) and the source are credited.

\section{References}

Allen DT, Consoli FJ, Davis GA, Fava JA, Warren JL (1995) Public policy applications of life cycle assessment. SETAC, Virginia, USA, ISBN 1-880611-18-X

Ammenberg J, Sundin E (2005) Products in environmental management systems: drivers, barriers and experiences. J Clean Prod 13 (4):405-415

Baumann H (1996) LCA use in Swedish industry. Int J Life Cycle Assess 1(3):122-126

Baumann H, Tillman AM (2004) The hitch hiker's guide to LCA. An orientation in life cycle assessment methodology and application. Studentlitteratur, Lund, Sweden. ISBN 91-44-02364-2

Bieda B (2011) Life cycle inventory of energy production in ArcelorMittal steel power plant Poland S.A. in Krakow Poland. Int J Life Cycle Assess 16(6):503-511

Czaplicka-Kolarz K, Bojarska-Kraus M, Wachowicz J (2004) A life cycle method for assessment of a Colliery's eco-balance. Int J Life Cycle Assess 9(4):247-253

de Bakker F, Fisscher O, Brack A (2002) Organizing product-oriented environmental management from a firm's perspective. J Clean Prod 10:455-464

Donnelly K, Beckett-Furnell Z, Traeger S, Okrasinski T, Holman S (2006) Eco-design implemented through a product-based environmental management system. J Clean Prod 14:1357-1367

EMAS Register (2009) http://ec.europa.eu/environment/emas/register/

Frankl P, Rubik F (1999) Life-cycle assessment (LCA) in business. An overview on drivers, applications, issues and future perspectives. Global Nest. Int J 1(3):185-194

Frankl P, Rubik F (2000) Life cycle assessment in industry and business: adoption patterns, applications and implications. Springer, Berlin. ISBN 3-540-66469-6

ISO (2010) The ISO survey of certifications 2009

ISO 14040 (2006) Environmental management-life cycle assessment - principles and framework. CEN, Brussels

Klöpffer W (2008) Life cycle sustainability assessment of products (LCSA). Int J Life Cycle Assess 13(2):89-95

Klöpffer W, Grahl B (2009) Ökobilanz (LCA): Ein Leitfaden für Ausbildung und Beruf. Wiley, ISBN-13: 978-3-527-32043-1

Klos Z (1999) LCA in Poland: background and state-of-art. Int J Life Cycle Assess 7(5):249-250

Klos Z (2000) First PhD thesis on LCA in Poland: ecobalancing of machines and devices with the example of air compressors. Int $\mathrm{J}$ Life Cycle Assess 5(1):19-20

Kulczycka J (2009) Life cycle thinking in Polish official documents and research. Int J Life Cycle Assess 14(5):375-378

Kurczewski P, Lewandowska A (2010) ISO 14062 in theory and practice - ecodesign procedure. Part 2: practical application. Int J Life Cycle Assess 15(8):777-784 
Lewandowska A (2011) Environmental life cycle assessment as a tool for identification and assessment of environmental aspects in environmental management systems (EMS). Part 1-methodology. Int J Life Cycle Assess 16(2):178-186

Lewandowska A, Matuszak-Flejszman A, Joachimiak K, Ciroth A (2011) Environmental life cycle assessment as a tool for the identification and assessment of environmental aspects in environmental management systems (EMS). Part 2-case studies. Int J Life Cycle Assess 16(3):247-257

Lundberg K, Balfors B, Folkeson L (2007) Identification of environmental aspect in an EMS context: a methodological framework for the Swedish National Rail Administration. J Clean Prod 15:385-394

Rocha C, Brezet H (1999) Product-oriented environmental management systems: a case study. J Sustain Prod Des 10:30-42

Shonnard DR, Kicherer A, Saling P (2003) Industrial applications using BASF eco-efficiency analysis: perspectives on green engineering principles. Environ Sci Technol 37:5340 5348

Swarr TE, Hunkeler D, Klöpffer W, Pesonen HL, Ciroth A, Brent AC, Pagan R (2011) Environmental life-cycle costing: a code of practice. Int J Life Cycle Assess 16(5):389-391

Wilfried K (2005) Product oriented ecological information systems and life cycle management. Quantitative and qualitative analyses in the German chemical and electrical industries. Progress in industrial ecology. Int J 2(1):89-106

Zobel T, Burman JO (2004) Factors of importance in identification and assessment of environmental aspects in EMS context: experiences in Swedish organisations. J Clean Prod 12:13-27

Zobel T, Almroth C, Bresky J, Burman JO (2002) Identification and assessment of environmental aspects in EMS context: an approach to a new reproducible method based on LCA methodology. J Clean Prod 10:381-396 